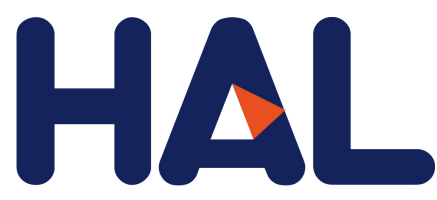

archives-ouvertes

\title{
Nerve Agent Sensors Sub-ppm Detection of Nerve Agents Using Chemically Functionalized Silicon Nanoribbon Field-Effect Transistors**
}

Simon Clavaguera, Alexandre Carella, Laurent Caillier, Caroline Celle, Jacques Pécaut, Stéphane Lenfant, Dominique Vuillaume, Jean-Pierre Simonato

\section{To cite this version:}

Simon Clavaguera, Alexandre Carella, Laurent Caillier, Caroline Celle, Jacques Pécaut, et al.. Nerve Agent Sensors Sub-ppm Detection of Nerve Agents Using Chemically Functionalized Silicon Nanoribbon Field-Effect Transistors**. Angewandte Chemie, Wiley-VCH Verlag, 2010, 49, pp.4063-4066. 10.1002/anie.201000122 . cea-01344100

\section{HAL Id: cea-01344100 https://hal-cea.archives-ouvertes.fr/cea-01344100}

Submitted on 11 Jul 2016

HAL is a multi-disciplinary open access archive for the deposit and dissemination of scientific research documents, whether they are published or not. The documents may come from teaching and research institutions in France or abroad, or from public or private research centers.
L'archive ouverte pluridisciplinaire HAL, est destinée au dépôt et à la diffusion de documents scientifiques de niveau recherche, publiés ou non, émanant des établissements d'enseignement et de recherche français ou étrangers, des laboratoires publics ou privés. 


\title{
Sub-ppm Detection of Nerve Agents Using Chemically Functionalized Silicon Nanoribbon Field-Effect Transistors**
}

\author{
Simon Clavaguera, Alexandre Carella, * Laurent Caillier, Caroline Celle, Jacques Pécaut, \\ Stéphane Lenfant, Dominique Vuillaume, and Jean-Pierre Simonato*
}

Organophosphorus compounds (OPs) represent one of the most important and lethal classes of chemical warfare agents (e.g. sarin, tabun, soman). Highly active volatile OPs are powerful inhibitors of acetylcholinesterase, which is a critical enzyme of the nervous system. ${ }^{[1]}$ The ease of manufacturing OPs based on inexpensive starting materials makes these agents a weapon of choice for terrorist attacks. ${ }^{[2]}$ Thus, the rapid sensing of these nerve agents has recently become an increasingly important research goal. Various approaches have been reported for the detection of these chemical warfare agents including colorimetric and fluorimetric spectroscopies, ${ }^{[3]}$ enzymatic assays, ${ }^{[4]}$ piezoelectric devices, ${ }^{[5]}$ single-walled carbon nanotube resistors ${ }^{[6]}$ and capacitors. ${ }^{[7]}$ However, these systems are plagued by limitations such as slow response time, moderate selectivity, operational complexity, or limited portability.

Field-effect transistors (FET) based on nanomaterials such as semiconducting nanowires, nanoribbons, or carbon nanotubes have been recently explored for chemical and biological detection. ${ }^{[8]}$ Their high effectiveness is mainly ascribed to an extreme sensitivity to electrostatic changes at the surface of the semiconductor and/or modifications of the Schottky barrier at the semiconductor/metal interface. A charge generation in the vicinity of the semiconductor of a FET is known to alter the electrical properties of the device. ${ }^{[9]}$ Several research groups have independently developed a series of small-molecule fluorescent sensors for OPs detection. ${ }^{[10]}$ They investigated organic moieties reactive towards OPs by formation of a phosphate ester intermediate and subsequent intramolecular nucleophilic substitution, which led to an ammonium salt and thus charge formation. We thought monitoring this charge generation with a functionalized FET could be a particularly promising approach. Herein,

[*] Dr. S. Clavaguera, Dr. A. Carella, Dr. L. Caillier, Dr. C. Celle, Dr. J.-P. Simonato

CEA Grenoble/LITEN/DTNM

17 rue des Martyrs, 38054 Crenoble Cedex 9 (France)

E-mail: alexandre.carella@cea.fr jean-pierre.simonato@cea.fr

Dr. J. Pécaut

CEA Grenoble/INAC

17 rue des Martyrs, 38054 Grenoble Cedex 9 (France)

Dr. S. Lenfant, Dr. D. Vuillaume

IEMN-CNRS, BP 60069

Avenue Poincaré, 59652 Villeneuve d'Ascq Cedex (France)

[***] We thank Nicolas Durrafourg for access to NMR instrumentation and Florian Nachon for helpful discussions.

0 orting information for this article is available on the WWW under http://dx.doi.org/10.1002/anie.201000122. we report the development of an OPs chemical sensor based on highly sensitive silicon nanoribbon field-effect transistors (SiNR-FETs) functionalized with compound 1 (Scheme 1).

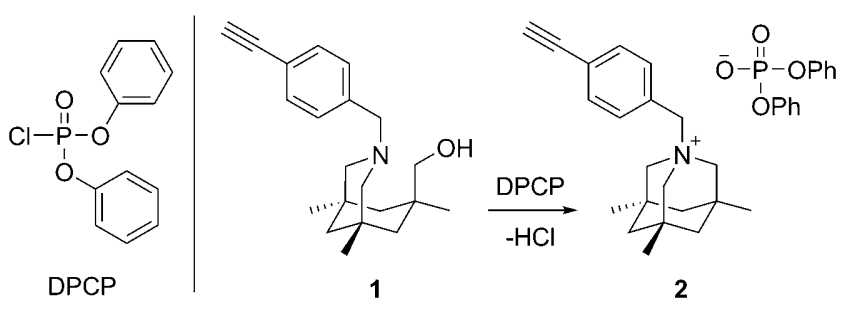

Scheme 1. Sensitive receptor towards OPs. Compound 1 converts into compound $\mathbf{2}$ upon exposure to OPs simulant (DPCP).

Compound $\mathbf{1}$, which is based on the scaffold developed by Dale and Rebek, ${ }^{[10 a]}$ was synthesized in four steps starting from the Kemp's triacid with an overall yield of $40 \%$. The ethynyl substituent was chosen to covalently graft the receptor to the semiconductor. Diphenylchlorophosphate (DPCP) was used as a simulant of nerve agents because of its similar structure and chemical reactivity, but much lower toxicity. Compound $\mathbf{1}$ reacted cleanly with DPCP and produced the azaadamantane quaternary ammonium salt $\mathbf{2}$ as confirmed by ${ }^{1} \mathrm{H}$ and ${ }^{31} \mathrm{P}$ NMR spectroscopy. The DPCP ${ }^{31} \mathrm{P}$ signal $(\delta=-5.8 \mathrm{ppm})$ decreased while the signal of the phosphate generated after reaction with 1 increased $(\delta=$ $-26.2 \mathrm{ppm}$ ). Monocrystals of $\mathbf{1}$ and $\mathbf{2}$ were analyzed by single-crystal X-ray analysis (Figure 1). ${ }^{[1]}$ In 1, a strong intramolecular hydrogen bond between the tertiary nitrogen atom and the hydroxy hydrogen atom $(\mathrm{N} \cdots \mathrm{H}$ distance is $1.950 \AA, \mathrm{N} \cdots \mathrm{O}$ distance is $2.805 \AA$ and $\mathrm{N} \cdots \mathrm{H}-\mathrm{O}$ angle is $178.1^{\circ}$ ) bends the adjacent cycle where five carbon atoms are nearly coplanar (average out-of-plane deviation $=0.01 \AA$ ). The nucleophilic power of the oxygen atom is probably enhanced because of the participation of the hydrogen atom in the intramolecular hydrogen bond. ${ }^{[12]}$ The azaadamatanium moiety in $\mathbf{2}$ is highly symmetrical ( $C_{3}$ axis) which corroborates the simplification of NMR signals from $\mathbf{1}$ to $\mathbf{2}$.

The SiNR-FETs were fabricated from $p$-doped $\left(10^{15} \mathrm{~B}\right.$ atom $\mathrm{cm}^{-3}$ ) silicon on insulator (SOI) wafers (Figure 2). SiNR-FETs of $70 \mathrm{~nm}$ thickness with different lengths and widths $(4 \times 4 \mu \mathrm{m} ; 4 \times 1 \mu \mathrm{m} ; 2 \times 1 \mu \mathrm{m}$, and $2 \times 0.2 \mu \mathrm{m})$ were obtained by using e-beam lithography and dry reactive-ion etching steps. The thickness of the $\mathrm{SiO}_{2}$ gate dielectric was $140 \mathrm{~nm}$. The $\mathrm{Ti} / \mathrm{Au}(10 / 100 \mathrm{~nm})$ source and drain contacts were achieved by using e-beam lithography and lift-off 

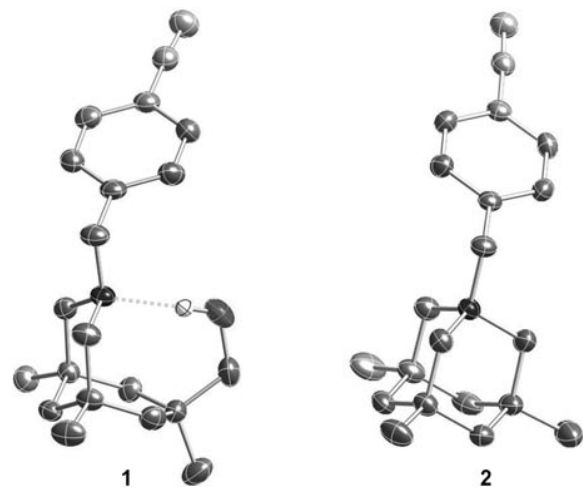

Figure 1. X-ray structures of $\mathbf{1}$ (left) and $\mathbf{2}$ (right). Hydrogen atoms and counter ions are omitted for clarity. The thermal ellipsoids are drawn at the $50 \%$ probability level.
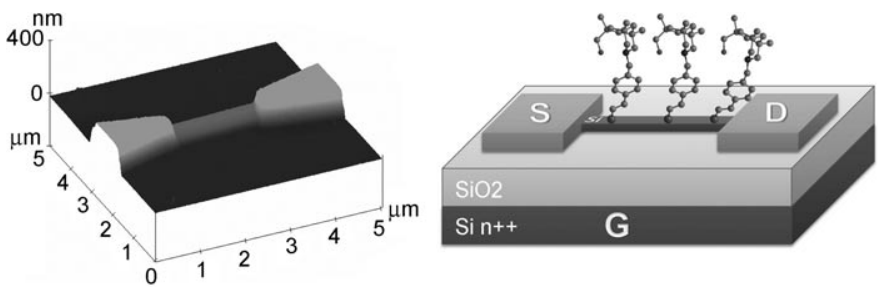

Figure 2. Left: AFM image of a SiNR-FET (70 nm thick, $2 \mu \mathrm{m}$ long and $1 \mu \mathrm{m}$ wide). Right: schematic view of FET device with source (S), drain $(\mathrm{D})$, and gate $(\mathrm{G})$ electrodes.

process. The Si degenerated substrate was used as the backgate electrode. The semiconducting part of the sensor was functionalized by covalent grafting through thermal hydrosilylation of $\mathbf{1}$ onto the HF-pretreated substrate in mesitylene at reflux for 2 hours.

In Figure 3, the drain-source current $\left(I_{\mathrm{DS}}\right)$ is plotted versus the back-gate voltages $\left(V_{\mathrm{GS}}\right)$ and shows that the device is ambipolar (electron(hole) conduction for positive(negative) back-gate bias, respectively). The exposure of functionalized SiNR-FETs to vapors of DPCP induced a strong modification of their transfer curves.

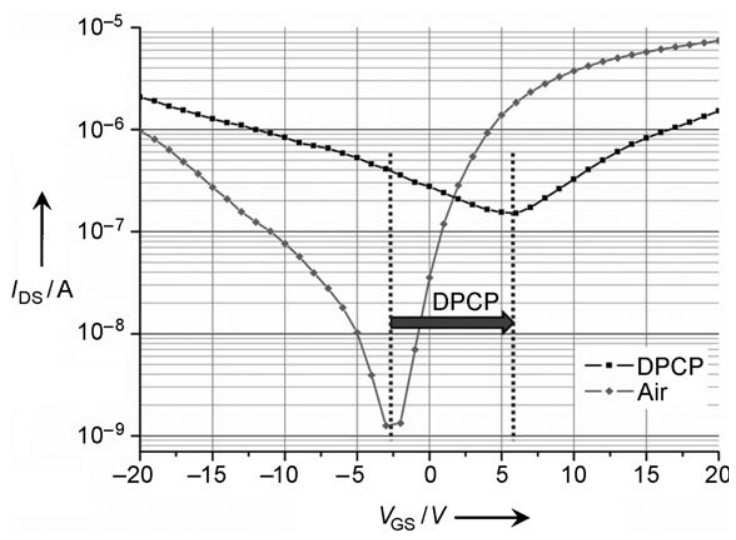

Figure 3. $4 \times 1 \mu \mathrm{m}^{2}$ functionalized SiNR-FET, $I_{\mathrm{DS}}-V_{\mathrm{GS}}$ curves at $V_{\mathrm{DS}}=-1 \mathrm{~V}$ before (diamonds) and after DPCP exposure (squares).
A statistical study on 30 nanoribbons was carried out and shows a clear trend upon exposure to vapors of DPCP. The $I_{\mathrm{DS}}-V_{\mathrm{GS}}$ curves are shifted to more positive gate-voltage bias. To simplify data handling, a particular gate voltage called $\mathrm{V}_{0}$, which corresponds to off-current minimum intensity $\left(I_{\mathrm{DS}}\right.$ $\min )$, was used. Figure 4 illustrates the shift of that particular

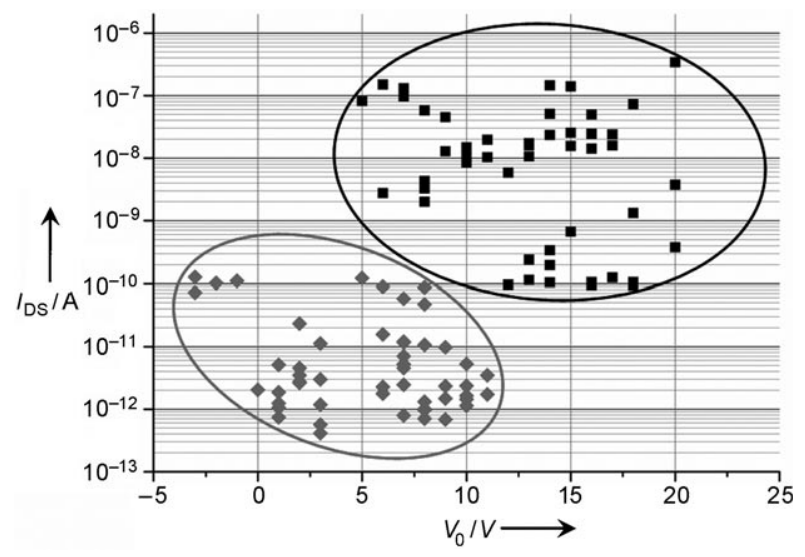

Figure 4. Functionalized SiNR-FET, $\left(V_{0} ; I_{D S} \mathrm{~min}\right)$ couples picked from $I_{\mathrm{DS}}-V_{\mathrm{GS}}$ curves at $V_{\mathrm{DS}}=-1 \mathrm{~V}$ before (diamonds) and after (squares) DPCP exposure.

gate voltage $\mathrm{V}_{0}$ before and after exposure to vapors of DPCP. One might observe that the scatter plots of the couples $\left(\mathrm{V}_{0}\right.$; $I_{\mathrm{DS}} \mathrm{min}$ ) before and after DPCP exposure are not covered. The $\mathrm{V}_{0}$ is consequently clearly shifted to more positive gate voltages after exposure to DPCP with an average variation $\Delta \mathrm{V}_{0}$ of $(7.3 \pm 3.5) \mathrm{V}$.

Modification of the drain current in a molecularly functionalized SiNR-FET can be a result of several factors: 1) creation of a net charge in the molecules which are acting as a virtual top gate; ${ }^{[13]} 2$ ) change in the density of the silicon surface states $;^{[9,14]} 3$ ) charge transfer between Si and molecules, which leads to interface dipoles and change in the silicon surface potential. ${ }^{[15]}$

In our case, positive charges are created on top of the monolayer of compound $\mathbf{1}$ after treatment with DPCP (see Scheme 1), which can eventually act as a virtual top gate for the SiNR-FET. However, a negatively charged counter-ion is also created and the monolayer is likely to remain neutral. Thus, factor 1) may be excluded here. As the reaction of DPCP with compound $\mathbf{1}$ does not change the nature and density of grafting links between $\mathbf{1}$ and silicon, factor 2) can be also excluded. Charge transfer at the molecule/substrate interface is a well-known effect ${ }^{[15]}$ and any change in the chemical structure of the molecule (i.e. upon reaction with DPCP) is likely to modify this charge transfer and the resulting interface dipole. Here, we assume that upon reaction with DPCP, and probably because of the presence of a positive charge on the $\mathrm{N}$ atom, some electrons are transferred from the Si to the molecules. As a consequence, this leads to more holes in the Si channel when the SiNR-FET is working in accumulation (p-type behavior at $V_{\mathrm{GS}}<\mathrm{V}_{0}$ ), and less electrons at $V_{\mathrm{GS}}>\mathrm{V}_{0}$ (n-type behavior). This observation is consistent with the current increase(decrease) experimentally 
observed at negative(positive) back-gate voltages, respectively. The amplitude of this charge transfer can be estimated as follows; the created interface dipole induces a modification of the surface potential $\Delta \varphi$ according to:

$\Delta \varphi=\frac{\text { end }}{\varepsilon_{\mathrm{SAM}} A}$

with $e$ the elementary electron charge, $n$ the number of transferred charge per molecule, $d$ the size of the interface dipole (between its two sides), $\varepsilon_{\mathrm{SAM}}$ the dielectric constant of the self-assembled monolayer (SAM), and $A$ the area per molecule. We assume that $d$ is of the same order of magnitude as the distance between the positive charges localized on the $\mathrm{N}$ atom of compound $\mathbf{1}$ and the silicon surface and can be estimated to $d=0.7-0.8 \mathrm{~nm}$. We take $\varepsilon_{\mathrm{SAM}} \approx 2.0-2.5$, a usual value for organic monolayers. Without a precise knowledge of the molecular organization and packing inside the monolayer of 1 (or 2), and accordingly to the size of the molecule elucidated by X-ray crystallographic data (we assume here that the tilt angle of the molecule with respect to the surface normal is $\theta=0^{\circ}$ ), we can calculate an average molecular density of approximately $N_{\text {calc }} \approx 2.8 \times 10^{14}$ molecules.cm ${ }^{-2}$, that is, $A \approx 35 \AA^{2}$. We have not a direct measurement of $\Delta \varphi$, but we can estimate it from the shift of the back-gate voltage. Considering the classical scaling rules of the FET device, a potential change of $\Delta \varphi$ at a distance $d$ (through a material with a dielectric constant $\varepsilon_{\mathrm{SAM}}$ ) from the Si channel (virtual top gate) is roughly equivalent to a change $\Delta V_{\mathrm{GS}}$ of the backgate voltage through a gate oxide $t_{\mathrm{ox}}$ (dielectric constant $\varepsilon_{\mathrm{ox}}$ ) if $\Delta V_{\mathrm{GS}}=\left(t_{\mathrm{ox}} / d\right)\left(\varepsilon_{\mathrm{SAM}} / \varepsilon_{\mathrm{ox}}\right) \Delta \varphi$. With $t_{\mathrm{ox}}=140 \mathrm{~nm}, \quad \varepsilon_{\mathrm{ox}}=3.9$, a back-gate shift of approximately $7.3 \mathrm{~V}$ corresponds to $\Delta \varphi$ $\approx 70 \mathrm{mV}$. From Equation (1), we estimated that approximately $4 \times 10^{-3}$ electron/molecule are transferred from Si to the molecules (or equivalently, ca. $1.1 \times 10^{12}$ electron. $\mathrm{cm}^{-2}$ ). While deduced using crude approximations, this value is in agreement with other results on functionalized silicon surfaces and devices. ${ }^{[15,16]}$ A more detailed analysis of SiNR-FET would require $2 \mathrm{D}$ device simulations, which is beyond the scope of this Communication.

The transfer characteristic of pristine SiNR-FETs presents no substantial deviation upon exposure to vapors of DPCP. The sensitivity of the SiNR-FET sensor is thus inherent to the chemical functionalization of the semiconducting channel.

An increase of $I_{\mathrm{DS}}$ min can also be observed upon exposure to DPCP vapors which could be ascribed to gate leakage. The $I_{\mathrm{GS}}-V_{\mathrm{GS}}$ measurements were carried out before and after exposure to vapors of DPCP, they show no significant variation (see Figure S6 in the Supporting Information). However, as after exposure $\mathrm{V}_{0}$ is shifted towards more positive values and because $I_{\mathrm{GS}}$ increases with the gate voltage, a tiny part of the increase in the $I_{\mathrm{DS}}$ min can result from this gate leakage. We also surmise that the charge transfer at the silicon-molecule interface involved to explain the $I_{\mathrm{DS}}-V_{\mathrm{DS}}$ shift can also affect the off current, because charge density in the nanoribbon are modified by this interface dipole. For example, change in the conductance/ resistance value of a molecular-controlled functionalized semiconductor resistor (MOCSER) has already been observed upon exposure to gas. ${ }^{[17]}$

The design of FET sensors allows us to modulate the output by applying the optimum gate voltage and thus enhancing the response. Hence, $\Delta I / I_{0}$ is maximized at $\mathrm{V}_{0}$. In the case of Figure $3, \mathrm{~V}_{0}$ is at $V_{\mathrm{GS}}=-2 \mathrm{~V}$. At this gate voltage, $I_{\mathrm{DS}}$ increases by a factor of two to four orders of magnitude upon exposure to vapors of DPCP. ${ }^{[18]}$

To avoid charge-trap effects or Joule effect ${ }^{[19]}$ during the $I_{\mathrm{DS}}$ versus time measurement, we developed a pulsed acquisition mode. Figure 5 shows a stable $I_{\mathrm{DS}}$ before exposure

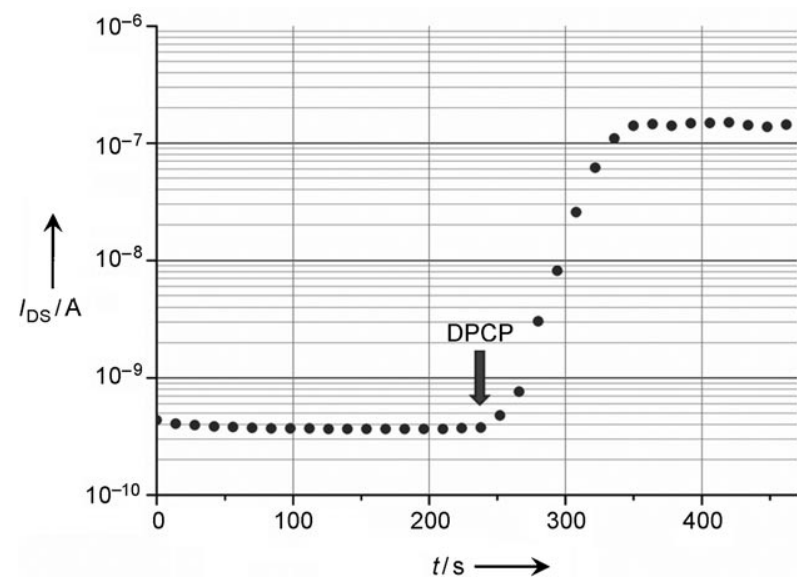

Figure 5. $4 \times 1 \mu \mathrm{m}^{2}$ functionalized SiNR-FET, $I_{\mathrm{DS}}$ measured in pulsed mode as a function of time $\left(V_{D S}=-1 \mathrm{~V}, V_{G S}=V_{0}=-2 \mathrm{~V}\right)$. DPCP vapors were introduced at $t=240 \mathrm{~s}$. The device is the same as in Figure 3.

to DPCP vapors. After exposure, $I_{\mathrm{DS}}$ rose immediately with a steep current increase and a plateau was reached within few tens of seconds. The signal remained stable, thus suggesting that all the chemical receptors had reacted. The small differences (i.e. a factor 2 to 4 ) between the currents $I_{\mathrm{DS}}$ before and after DPCP exposure measured by the pulsed method (Figure 5) and the ramp method (Figure 3) are usual $^{[20]}$ and have been ascribed to phenomena such as hysteresis, slow current drift, or local heating which affect the static method and not the pulsed one. It must be noted that the vapor pressure of DPCP was measured in the 500-800 ppb range, which reveals how sensitive these sensors are. Moreover, the sensor is cumulative, which is appropriate to OPs toxicity which poisons cumulatively the nervous system. ${ }^{[21]}$

Besides very good sensitivity, a crucial point in the realization of chemical sensors is to achieve high selectivity. The response of our sensor was evaluated for various common organic compounds and gases (Figure 6). No significant variation was observed for these molecules. It appears that the response of the sensor is much higher for DPCP compared to the other compounds. Moreover, it should be emphasized that the response under DPCP vapors was obtained at a subppm concentration (see above) while the sensor exhibited extremely weak responses for exposures to other compounds, at concentrations close to their vapor pressure ( $>20000 \mathrm{ppm}$, see Table S6 in the Supporting Information). As a conse- 


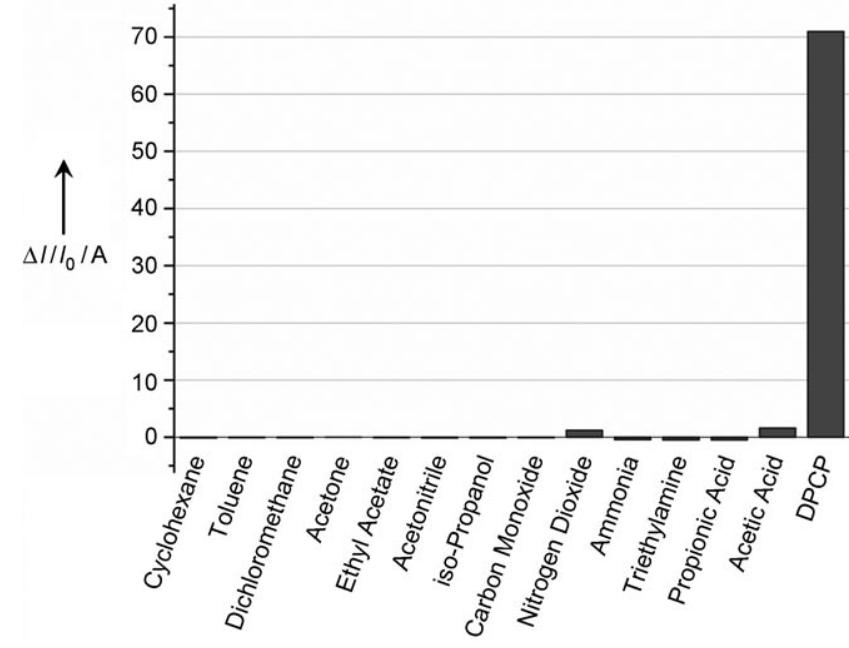

Figure 6. $I_{\mathrm{DS}}$ changes for a $3 \mathrm{~min}$ exposure to vapors of common organic compounds, gases, and DPCP at $25^{\circ} \mathrm{C}$ in air $\left(V_{D S}=-1 \mathrm{~V}\right.$, $V_{\mathrm{GS}}=\mathrm{V}_{0}$ ). All vapor pressures and gas concentrations are listed in Table S6 in the Supporting Information.

quence, we demonstrate that high selectivity can be obtained in combination with excellent sensitivity.

In summary, we have developed a highly sensitive and selective nerve agent sensor based on electrical transduction of a chemical reaction occurring on the surface of a functionalized SiNR-FET. The tiny semiconductor device, which operated at sub-ppm level of OPs simulant, showed a very fast and marked response which could be advantageously used for detection of Sarin-like agents. We hope this technology of hybrid sensors compatible with complementary-metal-oxide semiconductor (CMOS) technology will help to develop sensitive, compact, low-cost, and lowconsumption portable devices for widespread applications in the fields of defense and homeland security.

\section{Experimental Section}

Experimental details are given in the Supporting Information, including the synthetic procedures, device details, electrical characterizations, and crystallographic data for compounds $\mathbf{1}$ and $\mathbf{2}$. Functionalized SiNR-FETs were prepared from the SOI chip bearing silicon nanoribbons of various dimensions. The chip was sonicated in acetone then in isopropanol for $5 \mathrm{~min}$ prior to deoxidization with an immersion in $1 \% \mathrm{HF}$ aqueous solution for 20 seconds. The chip was thoroughly rinsed three times with deionized water and dried under argon flow. The treated chip was introduced in a mesitylene solution of $1(1.5 \mathrm{mg}$ in $10 \mathrm{~mL}, 0.5 \mathrm{~mm})$ and heated at reflux for $2 \mathrm{~h}$. The chip was washed successively with toluene, acetone, isopropanol, and dried under argon flow and stored in air prior to use.

Received: January 8, 2010

Revised: March 20, 2010

Published online: April 30, 2010

Keywords: field-effect transistors - nanotechnology . nerve agents $\cdot$ sensors $\cdot$ silicon nanoribbons
[1] C. P. Holstege, M. Kirk, F. R. Sidell, Crit. Care Clin. 1997, 13, $923-942$.

[2] R. J. Brennan, J. F. Waeckerle, T. W. Sharp, S. R. Lillibridge, Ann. Emerg. Med. 1999, 34, 191-204.

[3] a) K. J. Wallace, J. Morey, V. M. Lynch, E. V. Anslyn, New J. Chem. 2005, 29, 1469-1474; b) S. Royo, R. Martìnez-Màñez, F. Sancenòn, A. M. Costero, M. Parra, S. Gil, Chem. Commun. 2007, 4839-4847; c) T. J. Dale, J. Rebek, Jr., Angew. Chem. 2009, 121, 7990-7992; Angew. Chem. Int. Ed. 2009, 48, $7850-$ 7852.

[4] X. Ji, J. Zheng, J. Xu, V. K. Rastogi, T.-C. Cheng, J. J. DeFrank, R. M. Leblanc, J. Phys. Chem. B 2005, 109, 3793-3799.

[5] a) C. Hartmann-Thompson, J. Hu, S. N. Kaganove, S. E. Keinath, D. L. Keeley, P. R. Dvornic, Chem. Mater. 2004, 16, $5357-$ 5364; b) Q. Zhao, Q. Zhu, W. Y. Shih, W.-H. Shih, Sens. Actuators B 2006, 117, 74-79.

[6] a) J. P. Novak, E. S. Snow, E. J. Houser, D. Park, J. L. Stepnowski, R. A. McGill, Appl. Phys. Lett. 2003, 83, 4026-4028; b) F. Wang, H. Gu, T. M. Swager, J. Am. Chem. Soc. 2008, 130, $5392-$ 5393.

[7] E. S. Snow, F. K. Perkins, E. J. Houser, S. C. Badescu, T. L. Reinecke, Science 2005, 307, 1942-1945.

[8] a) N. Elfström, A. E. Karlström, J. Linnros, Nano Lett. 2008, 8, 945-949; b) K. S. Chang, C. C. Chen, J. T. Sheu, Y.-K. Li, Sens. Actuators B 2009, 138, 148-153; c) J. Du, D. Liang, H. Tang, X. P. A. Gao, Nano Lett. 2009, 9, 4348-4351; d) D. R. Kauffman, A. Star, Angew. Chem. 2008, 120, 6652-6673; Angew. Chem. Int. Ed. 2008, 47, 6550-6570.

[9] N. Elfström, R. Juhasz, I. Sychugov, T. Engfeldt, A. E. Karlström, J. Linnros, Nano Lett. 2007, 7, 2608-2612.

[10] a) T. J. Dale, J. Rebek, Jr., J. Am. Chem. Soc. 2006, 128, 45004501; b) S.-W. Zhang, T. M. Swager, J. Am. Chem. Soc. 2003, 125, 3420 - 3421; c) A. M. Costero, S. Gil, M. Parra, P. M. E. Mancini, R. Martìnez-Màñez, F. Sancenòn, S. Royo, Chem. Commun. 2008, 6002-6004.

[11] CCDC 760718 (1) and 760719 (2) contain the supplementary crystallographic data for this paper. These data can be obtained free of charge from The Cambridge Crystallographic Data Centre via www.ccdc.cam.ac.uk/data_request/cif.

[12] V. E. Anderson, M. W. Ruszczycky, M. E. Harris, Chem. Rev. 2006, 106, 3236-3251.

[13] O. Shaya, M. Shaked, A. Doron, A. Cohen, I. Levy, Y. Rosenwaks, Appl. Phys. Lett. 2008, 93, 043509.

[14] R. Cohen, L. Kronik, A. Shanzer, D. Cahen, A. Liu, Y. Rosenwaks, J. K. Lorenz, A. B. Ellis, J. Am. Chem. Soc. 1999, 121, 10545-10553.

[15] D. Cahen, R. Naaman, Z. Vager, Adv. Funct. Mater. 2005, 15, $1571-1578$.

[16] T. He, J. He, M. Lu, B. Chen, H. Pang, W. F. Reus, W. M. Nolte, D. P. Nackashi, P. D. Franzon, J. M. Tour, J. Am. Chem. Soc. 2006, 128, 14537-14541.

[17] D. G. Wu, D. Cahen, P. Graf, R. Naaman, A. Nitzan, D. Shvarts, Chem. Eur. J. 2001, 7, 1743-1749.

[18] A simpler detection output is the source-drain resistance of the device (Figure 3 at $V_{\mathrm{GS}}=0 \mathrm{~V}$ ). Indeed the $R_{\mathrm{SD}}$ value decreases by one order of magnitude upon exposure to vapors of DPCP which is already a significant value.

[19] I. Park, Z. Li, A. P. Pisano, R. S. Williams, Nano Lett. 2007, 7, 3106-3111.

[20] a) D. Estrada, S. Dutta, A. Liao, E. Pop, Nanotechnology 2010, 21, 085702; b) C. Petit, D. Zander, K. Lmimouni, M. Ternisien, D. Tondelier, S. Lenfant, D. Vuillaume, Org. Electron. 2008, 9, 979-984.

[21] D. E. Lenz, D. Yeung, J. R. Smith, R. E. Sweeney, L. A. Lumley, D. M. Cerasoli, Toxicology 2007, 233, 31-39. 